\title{
Novos partidos: em busca de uma definição conceitual
}

\section{Introdução}

$\mathrm{O}$ artigo tem como objeto os novos partidos. De modo mais preciso, discute o modo como a literatura os define, com vistas a fornecer subsídios que tornem a categoria teoricamente orientada e metodologicamente operacional, especialmente para investigações sobre o sistema político brasileiro, no qual o fenômeno é recorrente desde a reforma partidária de 1979.

Como o artigo pretende demonstrar, embora aparentemente a resposta sobre a definição de novos partidos seja evidente, de modo a não produzir grandes dificuldades conceituais e metodológicas, a realidade empírica se mostra mais nuançada e lança constantes desafios aos pesquisadores sobre como considerar os casos concretos. Como apontam Barnea e Rahat (2010, p. 305), "se 'novos partidos' é uma categoria analítica distinta, a questão 'o que constitui um novo partido?' [...] deve ser abordada"2.

O problema é como delimitar esta categoria para torná-la metodologicamente apta a classificar as diferentes conformações institucionais que os partidos apresentam e dimensionar com acuidade os efeitos que as novas legendas produzem nos sistemas partidários. Para ilustrar alguns desafios a serem enfrentados: partido que troca de nome deve ser considerado novo? E aquele que se funde com outro?

\footnotetext{
1 Programa de Pós-Graduação em Ciência Política, Universidade Federal de Pelotas, Pelotas, RS, Brasil. <albarret.sul@gmail.com>

2 Todas as citações de textos escritos originalmente em outro idioma foram traduzidas livremente pelo autor do artigo
} 
Quando uma legenda deixa de existir e surge outra com as mesmas lideranças, trata-se de um novo partido ou é o antigo renovado?

A investigação está baseada na contribuição de diferentes analistas internacionais que se debruçaram sobre a questão desde o final dos anos 1970. Foi a partir desse período que os até então considerados congelados sistemas partidários europeus (LIPSET; ROKKAN, 1967) viram surgir os partidos Verdes e os da chamada direita radical, o que pôs em xeque alguns dos pressupostos dessa teoria.

Houve, então, a crescente preocupação de analisar o advento desse fenômeno nas chamadas democracias ocidentais estáveis, a partir de uma série de estudos empíricos. A questão também mobilizou pesquisadores que abordam aqueles surgidos dos escombros do mundo soviético. No entanto, defrontaram-se com uma questão anterior e basilar para o desenvolvimento dos desenhos de pesquisa e a validade dos resultados alcançados: definir as condições necessárias e suficientes que compõem a concepção de novo partido.

Nesse percurso, a literatura se desenvolveu em torno de três unidades de análises diferentes, mas interligadas, o que acirrou as dificuldades para a formulação de um conceito unívoco. A primeira está centrada nos países e procura identificar quais variáveis sociais, de contexto político e/ou institucionais contribuem para que ele ocorra (HARMEL; ROBERTSON, 1985; HARMEL, 1985; van BIEZEN; RACHKOVA, 2014; AÏT-AOUDIA, 2016). A segunda foca no sistema partidário e se preocupa em dimensionar o impacto do advento de novos partidos para a dinâmica da competição política e a estabilidade do sistema democrático (TAVITS, 2006; POWELL; TUCKER, 2014; BOLIN, 2014; MARINOVA, 2015). A terceira toma os próprios partidos como prioritários, observando o modo como eles se organizaram, institucionalizam-se e as propostas que apresentaram (SIKK, 2005; MUSTILLO, 2009; BOLLEYER, 2013; BOLLEYER; BYTZEK, 2013).

Todas essas investigações são perpassadas pela discussão normativa em torno do papel que os partidos devem desempenhar na sociedade, de modo que elas ambicionam saber se as novas legendas surgem para respaldar demandas sociais não contempladas pelas 
ofertas já existentes, a indicar um déficit no sistema político (HUG, 2000; 2001), ou se são reorganização de propostas já conhecidas, impulsionadas por novas lideranças ou transmitidas por novas estratégicas comunicacionais, seguindo a perspectiva de que as democracias estáveis são um mercado aberto a novas ofertas.

Para alguns, apenas os primeiros podem ser efetivamente considerados novos partidos, pois são programática e institucionalmente novos. Para outros, menos exigentes, apenas o fato de serem novas organizações é suficiente para os classificar como tais (TAVITS, 2006; BOLLEYER; BYTZEK, 2013; BOLLEYER, 2013; HARMEL, 1985; HARMEL; ROBERTSON, 1985; KROWEL; LUCARDIE, 2008).

A normatividade se desdobra em duas dimensões de investigação: observar as condições facilitadoras para o advento de novos partidos e para o desempenho eleitoral que eles alcançam ${ }^{3}$. Essas dimensões são abordadas como dois momentos distintos e que podem ser produzidos por motivações também distintas, de forma que alguns estudos se centram em ambas (HARMEL; ROBERTSON, 1985; HARMEL, 1985) e outros em apenas em uma delas, como é o caso do custo de entrada, abordado por Tavits (2006), ou o da performance que os novos partidos alcançam, como em Bolleyer (2013), Bolleyer e Bytzek (2013), van Biezen e Rashkova (2014).

Um dos principais impasses dessa literatura é que concepções divergentes sobre o que sejam os novos partidos produzem desenhos de investigação diferentes e, consequentemente, resultados que não são plenamente comparáveis. O conjunto dessas pesquisas forma um caleidoscópio em que, embora todos falem de novos partidos e aparentemente se refiram ao mesmo objeto, efetivamente não o estão a fazer, e sim a construir diferentes e às vezes incompatíveis versões do que constitui esta categoria.

3 O desempenho costuma ser medido pelas noções de sucesso/fracasso ou significativo/insignificativo, mas também elas são fixadas de modo diferente pelos autores. Alguns tem como indicador a obtenção de uma determinada votação em uma ou mais de uma eleição legislativa nacional como 2\% para Powell e Tucker (2014); 4\% para Kitschelt (1989); 5\% para Marinova (2015). Outros a medem pela obtenção de representação parlamentar (BOLIN, 2014), pelo tamanho da bancada conquistada em séries mais longas, medida pela sustentabilidade, ou seja, a manutenção da bancada após alcançar representação (BELLOYER, 2013; BELLOYER; BYTZEK, 2013), ou, ainda, pelo tipo de trajetória eleitoral-parlamentar desenvolvida (MUSTILLO, 2009) 


\section{Definição}

Uma primeira contribuição que se dispõe a definir os novos partidos pode ser encontrada em Hug (2000, p. 193; 2001, p. 14). Ele fixou como critério de decisão considerar como tal aquele que apresenta candidatos pela primeira vez em uma eleição parlamentar de âmbito nacional ${ }^{4}$. Mustillo (2009, p. 317) a torna ainda mais específica: ele aborda somente aqueles que concorrem à câmara baixa e exclui os que somente participam da eleição presidencial e/ ou para o senado ${ }^{5}$. Trata-se de uma versão mais delimitada daquela formulada por Harmel (1985, p. 405), segundo a qual são novos partidos todos aqueles que foram adicionados ao sistema partidário original de um país ${ }^{6}$.

O critério adotado por Krouwel e Lucardie (2008, p. 280) é mais lato: inclui os partidos criados entre 1989 e 2006 que disputaram eleições, mas também aqueles que, já tendo concorrido, conquistaram representação parlamentar apenas nesse período ${ }^{7}$. Tal decisão não é muito consistente, pois considera equivalentes dois elementos distintos e dissociáveis no tempo (disputar pleito e

4 O estudo de Hug abarca 22 países democráticos do pós-guerra até 1997 (Alemanha, Áustria, Bélgica, Dinamarca, Espanha, Finlândia, França, Grã-Bretanha, Grécia, Holanda, Islândia, Itália, Luxemburgo, Noruega, Portugal, Suécia, Suiça, Great Britain, mais Canadá, Estados Unidos, Austrália e Nova Zelândia), tendo por objetivo desenvolver um modelo capaz de explicar o processo de formação dos novos partidos e o sucesso que eles alcançam. Para o autor, trata-se de um jogo relativo à interação entre partidos estabelecidos e os que pretendem criar novos partidos, o qual encontra estímulo em determinadas variáveis sociais e institucionais, como custos de formação e cláusula de exclusão menores.

5 Aborda quatro países latino-americanos (Bolívia, Equador, Chile, Venezuela), tendo como recorte temporal os anos de 1958 a 2005, aplicável conforme o período em que cada um vivenciou eleições democráticas. No total, abarca 32 eleições e 950 novos partidos, preocupando-se em classificar a trajetória eleitoral-parlamentar que obtiveram e sem abordar o processo de formação deles.

6 Harmel produziu dois artigos sobre o tema. O primeiro, mais "conceitual", opera como a introdução ao segundo, que escreveu em conjunto com Robertson (1985), no qual apresenta os resultados da investigação empírica. Identifica 223 partidos formados em 19 europeias e anglo-americanas, entre 1960 e 1980, e testa as causas e as condições para o advento dessas organizações e o sucesso que alcançam. A unidade de análise é os países e trabalha com variáveis sociais (tamanho e heterogeneidade da população etc.) e político-estruturais (número efetivo de partidos, tipo de sistema eleitoral, acesso à disputa etc.).

7 A investigação tem o recorte temporal citado, mas inclui legendas criadas nos anos 1970 e que obtiveram representação no período estudado. Aborda unicamente a Holanda e se dispõe a classificar a motivação dos fundadores dos novos partidos, a propor uma tipologia dessas legendas e relacionar o sucesso que obtiveram com as modalidades propostas de novo partido. 
formar bancada), os quais abrangem o cumprimento de exigências legais e políticas diferentes.

Uma das peculiaridades da definição de Hug $(2000,2001)$ é que ela distingue analiticamente (e temporalmente) duas dimensões da "vida" dos partidos: criação institucional e participação em eleições. Em reforço, Mustillo (2009, p. 316-317) faz a ressalva de que disputar pela primeira vez a eleição nacional não implica que a instituição tenha sido recém-criada: ela poderia contabilizar experiência como competidora em pleitos subnacionais, bem como poderia ter sido fundada há algum tempo e, por alguma razão, nunca ter disputado uma eleição.

Esses elementos fazem eco ao que sugere Pedersen (1982, p. 6-7). Antes de uma legenda ter acesso à eleição, há duas etapas prévias: a de declaração, que se refere ao momento em que ganha publicidade a intenção de criá-la; e a de autorização, correspondente a quando ela cumpre os requisitos legais exigidos pelo país e se torna oficialmente um partido. Essas dimensões podem estar mais ou menos distanciadas no tempo do primeiro pleito disputado, seja por vontade do próprio partido, seja por causa de fatores externos, como a ausência de eleições e/ou de autorização para o funcionamento dessas instituições, o que é comprovado pela história de países que vivenciaram períodos ditatoriais.

Pedersen (1982) cita uma terceira etapa, que é a obtenção de representação parlamentar, o que reforça a crítica apresentada ao critério adotado por Krouwel e Lucardie (2008) e que mistura participação em eleição com obtenção de bancada. Para o autor, há ainda uma quarta dimensão na vida de um partido, que é alcançar relevância parlamentar.

A definição de Hug $(2000,2001)$ está baseada em partidos eleitorais. Pode-se compreender essa escolha porque os estudos desenvolvidos a partir dela estão centrados exclusivamente no evento eleições e, mais do que isso, abordam exclusivamente democracias ocidentais identificadas como estáveis. Hug (2000, p. 6) o deixa muito claro: não analisa a formação de sistemas partidários em novas democracias, cuja dinâmica é, segundo ele, diferente da 
apreciada, e se restringe às circunstâncias em que novos desafiantes surgem em modelos já estabelecidos.

Ao mesmo tempo, a decisão estabelece um ponto de corte que circunscreve o fenômeno a determinados cenários e nitidamente exclui outros. Por consequência, limita o escopo de análise e empobrece a amplitude do conceito. Trata-se de uma decisão que garante consistência metodológica à investigação, mas cobra um preço em termos epistemológicos.

A título de explicitação: a escolha faz com que os partidos oficializados e que ainda não participaram de pleitos nacionais não sejam considerados novos partidos. Cabe questionar como esses partidos podem ser considerados - alguns com relevante atuação parlamentar, situação corriqueira no caso brasileiro, em que legendas são criadas por iniciativa de reorganização da elite política, sem que tenham passado como tais pelo crivo da vontade popular, o que ocorre apenas em um momento posterior ${ }^{8}$. Da mesma forma, constata-se que esta definição não está plenamente adequada a cenários distintos ao das democracias estáveis, nos quais interrupções ou a ausência de um calendário eleitoral são possíveis ou recorrentes.

A definição formulada por Aït-Aoudia (2016, p. 2) é alternativa, pois não está vinculada às eleições ${ }^{9}$. Seguindo os passos da de Harmel (1985, p. 405), a autora afirma que ela compreende "qualquer um [partido] que tenha sido criado mais recentemente, em um contexto político e institucional em evolução, e que se baseia em uma identidade política que, até aquele ponto no tempo, tinha estado ausente da arena política”.

Conforme esta definição, ela também considerou como novo um partido que decidiu não participar da disputa. Ou seja, o ponto de corte é o segundo estágio da vida partidária sugerido por Pedersen

8 Um exemplo histórico: todos os partidos criados imediatamente após a reforma partidária de 1979 que extinguiu Arena e MDB (PMDB, PP, PDS, PDT, PTB, PT) foram, primeiro, legendas parlamentares e somente alguns anos depois, em 1982, tornaram-se partidos eleitorais ao serem testados nas urnas.

9 A autora aborda a primeira eleição pluralista (livre e limpa, com resultado incerto e que teve competidores autônomos em relação ao governo), realizada na Argélia, em 1990 (subnacional), que se seguiu a um longo período autoritário. 
(1982), o registro como tal, e não a participação em eleições, como ocorre no caso dos autores anteriores ${ }^{10}$.

Este enunciado é coerente com o modo como Harmel (1985, p. 406) e Harmel e Robertson (1985, p. 507) operacionalizam a noção de partido: uma organização que tem como um de seus objetivos a colocação de seus membros em postos governamentais. Embora o meio mais convencional de alcançar este fim nos sistemas democráticos seja pela disputa de eleições - o que corresponde ao sentido atribuído por Hug $(2000,2001)$ e Mustillo (2009) -, não se trata de uma necessidade imperiosa, pois pode ser obtido sem essa exigência ou quando o partido ainda não participou de eleições, ainda mais se ele se origina como dissidência de bancada já estabelecida.

Barbea e Rahat (2010, p, 308) indicam que todas essas definições apresentam limites e lacunas. Eles as observam por outra perspectiva, aquela alusiva às distintas acepções de "novo":

O dicionário define o adjetivo 'novo' ou em termos cronológicos, como algo que 'veio recentemente a existir', ou em termos relativos, como 'sendo outro do que o antigo ou o velho', ou como sendo 'diferente de um da mesma categoria que existia anteriormente' (Merriam-Webster Dictionary). A definição cronológica aponta para um pré-requisito - para que algo seja novo, deve ser recente. A definição relativa, por outro lado, toca no núcleo da questão. Implica que, para algo ser novo, deve ser 'outro do que o velho', deve ser 'diferente'. Portanto, para definir o 'novo' devemos distingui-lo do 'antigo', 'velho' ou 'pré-existente' (BARNEA; RAHAT, 2010, p. 308) [em itálico no original].

Os resultados empíricos a que chegam a partir desta reflexão serão observados na sequência do texto. De momento, cabe destacar

10 É do autor do artigo a interpretação de que a definição abarca a oficialização, o que pode envolver o simples registro como entidade civil ou o reconhecimento pela autoridade eleitoral, conforme as exigências de cada país. Os casos analisados pela autora levam a crer que, para ela, basta a criação, pois um partido só foi legalizado após o pleito estudado. Em qualquer situação, o novo partido surge antes (e independe) da participação em eleição. 
que, para eles, um dos caminhos utilizados pelos investigadores é "assumir novidades com reservas", ou seja, basear-se tão somente na ordem cronológica. Logo, os partidos são novos porque não existiam na condição de competidores em eleições parlamentares nacionais anteriores, independentemente do quão iguais ou não eles são em relação aos antigos. Como visto, esta condição não implica que o partido seja recente, isto é, recém-criado - ao contrário do que apontam Barnea e Rahat (2010) -, mas sim que ele não participou do pleito nacional anterior e que, portanto, é cronologicamente novo nesse ambiente específico.

Na mesma linha: a definição de Aït-Aoudia (2016) dá margem a supor que contempla as duas dimensões destacadas por Barnea e Rahat (2010), ao enfatizar a criação recente e o fato de esses partidos agregarem uma identidade política até então ausente. Contudo, ela não traz critérios para dimensionar o que configura "criação recente" e tampouco especifica o que seja "identidade ausente da arena política", o que a torna lacunar neste aspecto.

Barnea e Rahat (2010, p. 309) consideram que

essa abordagem é atraente em sua simplicidade e inclusão - tudo é novo até provar em contrário. [...] Esta abordagem também é problemática conceitualmente, pois pode esticar o conceito 'novo' a ponto de não ter uma definição significativa ou um valor analítico.

Ao contrário do que argumentam os autores, na definição de Hug $(2000,2001)$ a lacuna relativa à segunda acepção do adjetivo - o quanto os novos partidos são diferentes dos já existentes - é suprida quando ele (e também outros pesquisadores que tratam do tema) distinguem as modalidades de novos partidos, o que os leva a discutir a "origem" ou o "status institucional" dessas instituições. Ou seja, ainda que não explicitamente considerada, a questão está no elenco de reflexões que fundamenta a definição. 


\section{As modalidades de novos partidos}

A partir dessa base, os autores se defrontam com questões teórico-metodológicas relativas a quais tipos de entidades efetivamente podem ser consideradas novos partidos e sob quais circunstâncias. É a discussão sobre as modalidades dessas organizações.

Segundo Hug (2001, p. 13-14), os novos partidos podem ser distinguidos em duas modalidades. A primeira é a dos genuinamente novos, aqueles criados sem apoio de membros de partidos existentes. Na mesma concepção, Harmel e Robertson (1985) os denominam como partidos de "formação natural" e Krouwel e Lucardie (2008), de "nascimento", ou seja, como tendo origem externa ao sistema partidário e ao parlamento. Em ambos os casos, eles seguem o clássico modelo fixado por Duverger (1987).

Sikk (2005, p. 399), por sua vez, define-os como aqueles que "não são sucessores de qualquer partido parlamentar anterior, têm um nome e uma estrutura novos, e não têm figuras importantes do período democrático anterior entre seus principais membros". Duas observações podem ser feitas a essa definição. A primeira é de que há a exigência de essa legenda ser recente e também diferente em relação às já existentes, como exigem Barnea e Rahat (2010). No entanto, o diferente diz respeito a aspectos formais (nome, estrutura e lideranças), mas não há referência a programa ou a ideias. A segunda é que ela está tão centrada nestes requisitos que considera que apenas os genuinamente novos são "novos", exclui as outras modalidades da categoria (que serão vistas na sequência), pois as classifica como formas que dão continuidade a partidos já existentes.

No seu estudo, Sikk (2005) se propõe a medir a volatilidade nos sistemas partidários dos países pós-comunistas, no qual a dinamicidade da disputa produz recorrentes cisões, fusões, alianças ocasionais e mudanças de nomes dos partidos ${ }^{11}$. Com vistas a separar esses fenômenos, ele enfatiza os genuinamente novos como os únicos inequivocadamente novos. Ainda que essa decisão possa

11 Especificamente, Sikk (2005) faz um estudo comparativo sobre a trajetória de quatro partidos de países bálticos: Nova União e Trabalhista (ambos da Lituânia); Nova Era (Letônia) e Res Publica (Estônia) 
ser considerada radical, ela está inserida na ideia de que eles não suscitam dúvida quanto a serem novos partidos e todas as demais sempre abarcam exceções, de modo que algumas de suas manifestações são excluídas dessa condição.

A segunda modalidade proposta por Hug (2001) é formada pelos que surgem da cisão de partido já existente, isto é, aquela legenda que é criada por pessoas que têm vínculo com alguma já estabelecida. Por isso, ela necessariamente possui origem interna ao sistema político-partidário. $\mathrm{O}$ critério é seguido por van Biezen e Rashkova (2014, p. 901) ${ }^{12}$, Bolleyer e Bytzek (2013) e Bolleyer $\left(2013\right.$, p. 44) ${ }^{13}$. Ressalva-se que Bolleyer (2013) considera que tal ocorre porque as cisões normalmente contam (ou são comandadas por) parlamentares e "[...] muitas vezes envolvem conflitos sobre políticas ou decisões estratégicas básicas ou, alternativamente, são o resultado de lutas de liderança”.

Há restrições a esta decisão. Além daquela apontada por Sikk (2005, p. 394), Marinova (2015, p. 5) desconsidera partidos oriundos de cisões como novos ${ }^{14}$. Outros pesquisadores justificam o posicionamento ao afirmar que nem todas as divisões geram novos partidos. É o caso de Hug (2001, p. 14): segundo ele, para que um partido formado por cisão seja assim considerado, é necessário que ele compita pelos mesmos votos com a agremiação da qual se separou. Na mesma linha, Powell e Tucker (2014, p. 129) afirmam que se o partido que se separa é um claro sucessor (por exemplo,

12 Van Biezen e Rashkova (2014) analisam o impacto das leis eleitorais sobre o sucesso que os novos partidos obtêm, tendo como foco 33 países da Europa Ocidental e do Leste - portanto, abarcam estáveis e novas democracias -, existentes entre 1967 e 2011. Elas concluem que a regulação não detém a formação de novos partidos, mas impacta no sucesso que eles obtêm.

13 Ambas as investigações abarcam 17 democracias (Alemanha, Áustria, Bélgica, Dinamarca, França, Finlândia, Grã-Bretanha, Holanda, Islândia, Irlanda, Luxemburgo, Noruega, Suécia, Suíça, mais Austrália, Canadá e Nova Zelândia), entre 1968 e 2011, estando voltadas a verificar a capacidade de o partido se sustentar com representação parlamentar após alcançá-la pela primeira vez, relacionando-a com variáveis como: origem da legenda, permissividade do sistema eleitoral, acesso a recursos públicos e à mídia.

14 Aborda 27 países europeus, entre 1987-2011, incluindo democracias estáveis e novas democracias, com a intenção de desenvolver um indicador empírico da instabilidade dos sistemas partidários. Por esta razão, defronta-se com o impacto da emergência de novos partidos, a desarticulação dos existentes, com a ocorrência de cisões e fusões, além da prática de coligações. 
tem o mesmo nome, controla os recursos do original), ele não é considerado um novo partido ${ }^{15}$.

No entanto, se dissidentes do claro partido sucessor emergirem como parte desse processo [...] então esses partidos são codificados como novos na primeira eleição da qual participam. [...] Em contraste, se um partido que participou de uma eleição no momento $t$ se divide sem um único sucessor, então todos os partidos sucessores daquele partido são considerados novos partidos no tempo $t+1$ (POWELL; TUCKER, 2014, p. 130).

Barnea e Rahat (2010, p. 309) não têm a mesma opinião. Para eles, classificações como esta - e outras, que serão indicadas - são inúteis para apontar a diferença efetiva entre partidos antigos e novos. Ao fazerem esta crítica, os autores parecem negligenciar o fato de que, para que o modelo no qual tais taxionomias se sustentam faça algum sentido, os partidos considerados genuinamente novos obrigatoriamente devem ser distintos dos já existentes (ao menos na condição de competidor), enquanto para aqueles oriundos de cisão a "novidade" é íntrinseca e instrumental: há a ideia que, se ele e aquele do qual se separou disputam o pleito, a condição de novo, isto é, de ser recente e distinto na competição está fixada, independentemente do quanto ele se difere dos partidos existentes.

Como se percebe, Barnea e Rahat (2010) trabalham a noção de novo partido como não somente recente, mas também "diferente", isto é, que deve portar algum tipo de distinção qualitativa em relação às legendas existentes. Desse modo, para eles, é possível que um partido recente (e que disputa a primeira eleição) não seja considerado novo.

15 A questão do "partido sucessor" será abordada na sequência via contribuição de Arter (2012). Antecipa-se que o caso reputado por Powell e Tucker (2014) não se trata propriamente de cisão, e sim de transformação, conforme modelo sugerido por Krouwel e Lucardie (2008). O estudo desses autores segue o objetivo buscado por Marinova (2015) e abarcou a análise da instabilidade do sistema partidário de 21 países pós-comunistas, medida pela volatilidade eleitoral. 
Para Hug $(2000,2001)$ e outros dos autores citados, a distinção primeira, fundamental e mais simples, é que ele não seja os outros, isto é, nunca tenha disputado uma eleição nacional como tal, o que o torna, no âmbito desta definição, cronologicamente novo, ainda que não o seja em termos concretos, isto é, que já existisse há algum tempo. E competir com os estabelecidos (notadamente o partido-mãe) é um critério suplementar para afirmar esta condição no caso dos oriundos de cisão. Na definição de Aït-Aoudia (2016), como já visto, os dois critérios se juntam: o novo partido deve ser recente e diferente (em relação aos já existentes), sendo que a novidade em termos cronológicos não implica estrear na eleição nacional, e sim ter sido criado há pouco tempo.

Ainda em relação às modalidades dos novos partidos, conforme a origem deles, ressalva-se que Hug (2000, p. 193; 2001, p. 13-14) não considera como tal aquele que surge em decorrência de fusão entre duas ou mais legendas previamente existentes. $\mathrm{O}$ autor pondera que tal partido formado traz uma "herança" fornecida pelos antecessores, no que é seguido por Sikk (2005, p. 394), Tavits (2006, p. 106; 2008, p. 122) ${ }^{16}$, Mustillo (2009, p. 317), Marinova (2015, p. 5) e Bolin $\left(2014\right.$, p. 8) ${ }^{17}$.

Bolin, aliás, argumenta que as fusões podem ser vistas como partidos estabelecidos que simplesmente se reorganizaram ou, em outras palavras, são os antigos concorrentes sob uma nova aparência - e, neste âmbito, ele converge com Barnea e Rahat (2010), quando demandam "novidade" (diferença) para a identificação de um novo partido.

16 A primeira investigação procura identificar as condições de entrada na arena eleitoral de novos partidos em 22 países (Alemanha, Áustria, Bélgica, Dinamarca, Finlândia, França, Grã-Bretanha, Grécia, Holanda, Islândia, Irlanda, Itália, Luxemburgo, Noruega, Portugal, Espanha, Suécia, Suiça, mais Austrália, Canadá, EUA e Nova Zelândia), entre 1960 e 2002. Baseada em Cox (1997), ela propõe três critérios de análise para que a elite partidária (fundadores e dirigentes) tome a decisão: custo de entrada, benefícios dos cargos a serem conquistados e a probabilidade de obter apoio eleitoral. A segunda pesquisa aprecia as mesmas variáveis, assim como o sucesso eleitoral dos novos partidos, em 15 países pós-comunistas de 1990 a 2004.

17 O foco do autor se centra exclusivamente nos novos partidos que alcançaram pela primeira vez representação parlamentar, em 18 democracias europeias, entre 1960 e 2010, buscando explicar as motivações pelas quais eles alcançam tal resultado. 
A questão de inserir ou não a fusão é polêmica entre os pesquisadores. Ao contrário dos vistos acima, Mair $(1990,1999)$ a considera como mais uma modalidade de novos partidos, o que também o fazem van Biezen e Rashkova (2014). Já Bolleyer (2013, p. 26), Bolleyer e Bytzek (2013, p. 779; 2016, p. 775) ficam no meio termo: incluem-na, mas não em todos os casos. As autoras retiram aqueles casos em que um partido já existente absorve outro(s), que deixa(m) de existir, pois os avaliam como a continuação de legendas estabelecidas. Como destaca Bolleyer (2013, p. 15), o critério fundamental para considerar como novo um partido oriundo de fusão é que a existência dele implique a "morte"18 dos envolvidos neste processo, isto é, a perda da autonomia organizacional que até então apresentavam e o surgimento de entidade que necessita construir uma infraestrutura viável, pois a fusão

pode decorrer de uma posição de fragilidade (sendo, na verdade, a única alternativa à dissolução) ou como um movimento estratégico de um partido, em princípio, autossuficiente para aumentar sua influência no sistema partidário ao aliar-se com outro partido representando problemas similares ou até os mesmos.

Com esta ideia, indica que coligações não formam novos partidos, embora, na prática, possam operar como tal, conforme as regras do país - e este é o caso do Brasil. Elas são a junção, muitas vezes episódica, de duas ou mais legendas que associam suas listas ou candidatos para acumularem votos, mas que mantêm as respectivas autonomias institucionais.

Powell e Tucker (2014, p. 129) compartilham a posição de considerar os partidos decorrentes de fusão como novos em determinadas circunstâncias, inclusive adotam o mesmo critério visto acima. Porém, eles a expressam de modo formal: o partido só pode ser

18 Para a autora, significa que o partido não mais apresenta candidatos porque se dissolveu (ao menos como partido, não necessariamente como organização), desintegrou-se (deixou de atuar como ator coletivo) ou fundiu-se com outro(s). 
classificado como novo se pelo menos dois dos envolvidos na fusão obtiveram pelo menos 5\% dos votos na eleição precedente. Se apenas um deles recebeu pelo menos $5 \%$ dos votos, o surgido da fusão é considerado uma continuação do partido maior sob outro nome.

Ao classificar as modalidades de novos partidos, os critérios adotados por Krouwel e Lucardie (2008, p. 279) são mais amplos do que os de Hug (2001). Ao invés de apenas duas modalidades (genuinamente novo e cisão), eles afirmam existir quatro graus crescentes de novidade nas legendas definidas como tal.

O primeiro é um tipo que ainda não foi abordado: por transformação. Ele corresponde a partido estabelecido que se renova, revisa seu programa, apela para novos grupos de eleitores e/ou muda de nome ${ }^{19}$. Esta sugestão acompanha a de Mustillo (2009, p. 318), que os caracteriza como partidos já existentes que são "tomados" por novas lideranças, perdem uma parcela significativa dos antigos filiados e dos líderes, sofrem mudança repentina de programa, de modelo organizacional e, às vezes, também de nome.

Os demais já são conhecidos: fusão, correspondente à união de um ou de mais partidos já existentes, formando um novo, que pode adotar denominação inédita ou utilizar o nome de um dos formadores; cisão, em que um ou mais setores de partido existente rompem com ele e formam nova legenda, assumem novo nome e elaboram nova plataforma política; e de nascimento, nos quais cidadãos sem vínculos com os partidos estabelecidos criam um novo $^{20}$.

Ao agregarem o "grau de novidade", Krouwel e Lucardie (2008) confirmam como novos partidos os tipos unanimemente aceitos dos genuinamente novos e dos oriundos de cisão (embora tal não

19 Não fica claro se os autores incluem as coligações como uma forma de transformação. Há indícios de que não, pois a modalidade exige mudança organizacional e as coligações, não. Sobre a questão, Marinova (2015, p. 4, nota 5) indica: "participar e sair de listas partidárias não altera a estrutura dos partidos, pois eles mantêm considerável independência organizacional, mesmo quando aparecem na mesma cédula eleitoral. No entanto, quando os partidos entram ou deixam listas, eles alteram o menu de alternativas de votação, de modo muito parecido com fusões e cisões de partidos".

20 Este também é o modelo adotado por Harmel e Robertson (1985, p. 509), ao denominá-los como circunstâncias da formação. Contudo, eles apenas propuseram as modalidades e não se preocuparam em defini-las com mais rigor. 
abarque todos os casos para alguns pesquisadores). Eles também acatam os originários de fusão - que divide mais intensamente os autores - e ainda se permitem acrescentar os decorrentes de transformação. Em cada tipo, além das diferenças produzidas pelo processo originário, associa-se a distinção em relação aos partidos já existentes.

O novo partido por transformação é a modalidade mais polêmica e a que tem menos adeptos dentre os pesquisadores. Krouwel e Lucardie (2008) a incluem porque consideram como novo o partido antigo que se transformou drasticamente, de modo a não ser mais reconhecido como era antes. Na mesma medida, indicam que nem todas as transformações fazem com que o produto da mudança seja um novo partido, algumas menos intensas não autorizariam a considerá-lo como tal. Há convergência entre a visão deles com a de Barnea e Rahat (2010), isto é, o grau de novidade deve ser critério para classificação. A diferença é que, para os últimos, ele deve adotado sempre.

Arter $(2012$, p. 805, 809) sugere uma variação do novo partido por transformação, que é chamada por ele de "partido sucessor", correspondente a aquele que é criado como substituto do antecessor que, por qualquer motivo, deixou de existir. Ele não é uma mera cópia do precedente, embora haja nítida semelhança entre ambos, no que tange a ideias, militantes e dirigentes. $\mathrm{O}$ sucessor minimamente adota um nome diferente e é legalmente registrado como um partido separado. $\mathrm{Ou}$, conforme define: "um partido que é nominalmente e legalmente uma nova entidade que toma o lugar e preenche alguns dos espaços políticos desocupados por um único e extinto partido de origem" (ARTER, 2012, p. 807) ${ }^{21}$.

Conforme o critério sugerido por Bolleyer (2013), o "partido sucessor" pode ser considerado um novo partido, pois surge da "morte" de outro e da vacância por ele deixada, o que não fica tão claro no modo como Krouwel e Lucardie (2008) caracterizam a

21 O autor desenvolve esta noção, adaptada da de partido sucessor comunista, e a aplicando a democracias europeias. Em termos empíricos, utiliza-a para analisar o caso do Partidos dos Verdadeiros Finlandeses (True Finns). 
modalidade por transformação ${ }^{22}$. A categoria proposta por Arter aprimora e distingue com mais propriedade que a sugerida pelos dois autores. Ainda assim, Bolleyer e Bytzek (2013, p. 778-779) rejeitaram o considerar como modalidade de novo partido.

Krouwel e Lucardie (2008, p. 281) ainda distinguem três possíveis origens para os partidos de nascimento - os genuinamente novos, no dizer de Hug (2001), ou naturais, no de Harmel e Robertson (1985). São elas: ramificação, realinhamento e empreendedorismo político. A ramificação ocorre quando uma organização política internacional decide desenvolver um ramo nacional. O realinhamento corresponde aos casos em que movimentos sociais ou grupos de pressão já atuantes decidem se transformar em partido. Já o empreendedorismo ocorre quando iniciativas privadas (muitas delas oriundas de um indivíduo) e que não possuem vínculos diretos com movimentos sociais, grupos de pressão ou organizações internacionais, decidem criar um partido.

Bolleyer $(2013$, p. 17, 40) adota praticamente o mesmo modelo, embora o dela seja mais enxuto, pois classifica os novos partidos em: (a) originários de empreendedorismo político, chamados empreendedoriais; (b) enraizados, provenientes de organizações sociais, sem que seja distinguido se elas são internacionais ou não, isto é, se são ramificação ou realinhamento, para usar a terminologia de Krouwel e Lucardie (2008).

Os novos partidos decorrentes de cisão ou de fusão são incluídos no mesmo modelo. Apesar de procederem de entidades existentes, eles também podem ter como impulso para criação ações empreendedoriais ou organizações sociais. No entanto, Bolleyer (2013, p. 41) faz um esclarecimento procedimental: partidos oriundos de cisão só foram classificados como enraizados, quando indícios apontavam a existência de uma base de apoio alheia ao partido-mãe, caso contrário, eles seriam considerados empreendedoriais.

22 A troca de nome, por exemplo, é critério apenas complementar para classificar um partido como novo, jamais definidor, pois muitos modificam a denominação (às vezes por meio de pequena alteração) como estratégia eleitoral, mas há a permanência de algumas características fundamentais: estrutura, dirigentes e, se tiver representação parlamentar, membros da bancada. 


\section{Novidade considerada como ser diferente em relação a outros}

A visão de Barnea e Rahat (2010) difere das que foram apresentadas até agora. Para estes autores, a questão temporal - ser recente - não é suficiente para considerar um partido como novo. O critério essencial para merecer tal classificação é o grau de novidade que apresenta um partido que nunca havia disputado uma eleição, pois ele pode ser uma antiga legenda renovada ou, então, pseudo-novo, como eles denominam ${ }^{23}$.

A questão dialoga com as modalidades de transformação, fusão e cisão, assim como implica desenvolver parâmetros para a análise de casos concretos. No artigo, eles não se debruçam sobre os genuinamente novos. No entanto, argumentam que nenhum partido é criado do nada e, por consequência, também essa modalidade demanda critérios mais rigorosos do que os normalmente utilizados, que consideram muito intuitivos.

Os autores propõem oito critérios para definir a novidade. A primeira diz respeito à interface com o eleitorado e analisa: (a) nome adotado - se ele é efetivamente inovador ou se contém a denominação de uma legenda antiga ${ }^{24}$; (b) ideologia - quão diferente é o programa, as questões e os valores apresentados na arena política; (c) eleitores - o quanto possui novas bases de apoiadores. A segunda dimensão se refere aos aspectos organizacionais: (d) registro legal - se está oficializado como uma nova entidade; (e) institucionalidade - se as suas instituições se diferenciam das apresentadas pelos partidos já estabelecidos; (f) militante - se ele possui novos ou se são "imigrados" de legenda anterior. A terceira

23 Como os autores seguem a trilha que considera novos partidos eleitorais, eles não fazem referência à possibilidade sugerida por Aït-Aoudia (2016) de incluir partidos que não disputam eleições.

24 O comentário de Barnea e Rahat (2010, p. 307) é: "aqui nós podemos distinguir três principais possibilidades. A primeira delas [...] um partido que retém seu antigo nome é visto a este respeito como um antigo partido. A segunda possibilidade é a de um partido que usa um nome novo, sem vestígios do antigo - possivelmente na tentativa de se dissociar do 'estabelecido' e de se identificar no mercado como uma nova alternativa. Tal partido é considerado novo a este respeito. Uma terceira possibilidade é a de um partido que opte por adotar um nome que inclua traços do passado. No caso dos partidos existentes, isso simboliza uma promessa de renovação do antigo, de modo a aumentar o seu apelo a novos grupos de eleitores, preservando a sua identidade aos olhos de seu eleitor leal e veterano". 
dimensão, relativa ao partido no governo, abarca: (g) representantes - se os principais candidatos são novos ou se a maioria ou todos vêm de um único partido; (h) políticas públicas - quão diferentes são as que ele apresenta em relação às já propostas no mercado partidário.

Alguns desses critérios são bastante questionáveis. No caso de determinar se o partido tem novas bases de apoiadores, o desafio é duplo: do ponto de vista metodológico, identificar quais foram as opções realizadas pelos eleitores em dois processos eleitorais diferentes; do ponto de vista conceitual, ele decorre do fato de que, inevitavelmente, os votos que o novo partido receber virão de quem escolheu outra legenda em pleito anterior. Alternativamente, os eleitores poderiam ter se abstido, votado em branco ou nulo e, na atual, serem atraídos pela nova opção eleitoral.

Entretanto, a intenção dos autores é justamente esta. Eles propõem que, empiricamente, o nível de "novidade" seja indicado ao distinguir a porcentagem daqueles que votaram na eleição prévia no partido-mãe (BARNEA; RAHAT, 2010, p. 307). A assertiva revela (e explica o problema conceitual identificado acima): eles circunscrevem os novos partidos àqueles decorrentes da divisão ou da fusão de legendas, mas, aparentemente, não consideraram a possibilidade de que partidos surjam sem referências a entidades precedentes. $\mathrm{Ou}$, alternativamente, pensam que, se é este o caso, o grau de novidade é pleno e, portanto, não cabe aplicar este e outros critérios. De qualquer forma, tal assertiva é contraditória com a afirmação deles de que nenhum partido nasce do nada.

Ao discutirem o partido como instituição, torna-se evidente que a preocupação diz respeito a aqueles que surgem de outros já existentes, pois ponderam:

a este respeito também, a extensão da novidade varia; ela pode ser encontrada em partidos antigos que reconstruíram suas instituições e em coligações de antigos partidos que amalgamaram suas instituições. Devemos reconhecer o primeiro caso como de novidade moderada. Níveis elevados 
de novidade serão identificados quando as instituições do novo partido ostensivo forem separadas e diferenciadas dos partidos antigos, ou seja, as instituições do partido originário continuarão a existir depois que as cisões estabelecerem suas próprias instituições (BARNEA; RAHAT, 2010, p. 307).

Considera-se que alguns dos critérios são equivocados ou pouco propícios à verificação empírica e, consequentemente, inadequados para o propósito que move os autores. A intenção de estabelecer critérios para dimensionar o grau de novidade pode ser útil para distinguir os novos partidos entre si, embora não pareça razoável como determinante para classificar as legendas como tal. Nesse aspecto, ainda que se possa discordar dos resultados alcançados, a sugestão de Krouwel e Lucardie (2008), vista anteriormente, está mais bem fundamentada.

Outra dificuldade que o estudo de Barnea e Rahat (2010) apresenta é não operacionalizar os parâmetros propostos e tampouco hierarquizá-los. Consequentemente, não oferece um modelo integrado de classificação do grau de novidade. Em outros termos: quantos dos oito critérios precisam ser cumpridos por um partido para que ele seja considerado novo? Como se relacionam entre si, se é que o fazem, aqueles categóricos (apresenta ou não) e aqueles que podem ser classificados em um continuum? E no caso destes, qual escala será utilizada?

No entanto, talvez as restrições aqui apresentadas sejam exageradas, pois os autores acabam por estabelecer um limiar no grau de novidade a partir do qual o partido é considerado novo. Ele reúne apenas dois critérios, o que indica serem os mais decisivos. Barnea e Rahat (2010, p. 311) conceituam como novo um partido que tem simultaneamente: (a) novo nome, isto é, aquele que não traz referências diretas a algum partido existente; (b) não mais de que 50\% dos seus principais candidatos (os que figuram no todo da lista ou em distritos seguros) são originários de um partido antigo.

Ainda que a restrição contida nessa exigência possa ser considerada demasiada e não se mostre sensível especialmente a casos 
de cisão (em que é razoável pensar que o segundo critério não seja preenchido), o problema como essa delimitação é outro. Os autores não sustentam convincentemente porque seguir especificamente esses dois critérios e dispensar os demais. E, de qualquer forma, a definição tem capacidade explicativa apenas para sistemas de lista fechada, hierarquizada e bloqueada, aqueles nos quais os partidos podem estipular previamente a ordem de preferência entre os seus candidatos.

O critério fornecido por Hug (2000, 2001) e Mustillo (2009) parece ser mais simples e eficiente: há novo partido sempre que ele disputa pela primeira vez uma eleição (nacional, no recorte oferecido por ambos). O mesmo pode ser dito do formulado por Aït-Aoudia (2016). E, todos, como já indicado, especificam o enunciado de Harmel (1985). Assim, a proposta de Barnea e Rahat (2010) de identificar o grau de novidade (ou de distanciamento em relação aos partidos estabelecidos) fornece indicadores para distinguir modalidades de novos partidos, mas não altera o que os configuram como tais. Portanto, ela não se presta para a intenção principal, que é ter um referencial para identificar se um partido recém-surgido pode ser considerado novo.

A eficiência da definição citada acima se manifesta nos elementos que ela fornece para distinguir as modalidades de novo partido. Ela propõe que, para ser genuinamente novo, o partido que disputa a primeira eleição nacional não pode ter relação clara com os que participaram do pleito precedente. Se for uma cisão, provavelmente o partido-mãe continua na disputa e ambos lutarão pelas preferências do eleitorado. Se for fusão, deve ocorrer o contrário - embora tanto Hug $(2000,2001)$ quanto Mustillo (2009) não o considerem um tipo de novo partido.

Seguindo a mesma linha: no caso de partido de transformação, conforme proposto por Krouwel e Lucardie (2008), é preciso verificar se os partidos dos quais ele se origina continuam na disputa. Se isto se confirmar, há evidência de que é uma nova legenda. No caso de partido sucessor, sugerido por Arter (2012), a expectativa é inversa: a legenda sucedida não estará na disputa. 
O problema existe quando os partidos-mãe não participam na disputa e é nesses casos de fusão, de transformação ou de partido sucessor que a contribuição de Barnea e Rahat (2010) fornece parâmetros para verificar se o partido surgido é ou não uma continuidade reformulada de legendas anteriores e, portanto, pode ou não ser considerado novo.

Porém, ao aplicarem os seus critérios a um caso concreto, Barnea e Rahat (2010, p. 311-313) expõem o equívoco do qual partem. Eles se dedicam a analisar se o partido israelense Kadima é novo, tendo em vista ser uma cisão do Likud. A conclusão é não ser novo, de fato. A necessidade de fazer uma extensa discussão sobre esta questão demonstra que os autores não têm clareza sobre o tema e explica o resultado inusitado a que chegaram, pois, se Kadima e Likud disputaram a mesma eleição, claramente são duas entidades (ou foram naquele momento) e o primeiro é um novo partido, independentemente das peculiaridades da sua relação com o partido-mãe e do quanto é novo (diferente) em relação a ele.

Se seguissem apenas um dos critérios que eles mesmos propuseram (o mais formal), relativo à obtenção do status legal, poderiam verificar que ambos foram considerados como tais, isto é, estavam oficializados como distintos competidores. Enfim, a minuciosa discussão levada a termo pelos autores, servindo-se de seus oito critérios, é desnecessária nesse caso. A polêmica que move a investigação poderia ser resolvida com muito mais facilidade.

O que pode explicar a análise realizada por Barnea e Rahat (2010, p. 314-316) é o objetivo de considerar o advento de novos partidos como indicador da mudança ou da instabilidade do sistema partidário. A assertiva diz que o surgimento de novo competidor que transita no mesmo patamar dos já existentes afeta a competição entre os partidos, mas não o elenco de programas oferecidas ao eleitor. E este seria o efetivo significado da exigência de que o novo partido deveria ser diferente dos já existentes.

Entretanto, os autores confundem indevidamente duas ordens distintas de abordagens sobre o tema. De um lado, o fato de o advento de novo partido na arena eleitoral afetar a competição entre 
as legendas é pressuposto óbvio - e recorrentemente destacado, como em Tavits (2006, p. 99). E, de qualquer modo, a intensidade desse fenômeno pode ser medida com mais facilidade e robustez por meio do índice de volatilidade. De outro, porque questionar a "novidade" em termos dos programas que o novo partido oferece ao eleitor aborda uma questão derivada. Afinal, o advento de nova legenda se manifesta por meio de opções que surgem no mercado eleitoral, independentemente do conteúdo (novo ou não) que ele traz ao eleitorado - aliás, em determinadas situações não precisa trazer conteúdo algum, basta ter um líder marcante para alcançar respaldo de votos. Com isto não se quer dizer que o tema da novidade programática seja irrelevante, mas sim que abarca questões de outra ordem.

Por derradeiro: ainda que a intenção de Barnea e Rahat (2010) fosse procedente, a proposta parece epistemologicamente equivocada, pois minimiza o impacto da competição interpartidária e faz do sistema partidário a unidade de análise preferencial, embora a investigação seja realizada em torno do(s) partido(s) individualmente considerado(s).

\section{Todos os partidos têm novidade}

O modelo de Barnea e Rahat (2010) pode ser comparado ao de Litton (2015), que parte de um pressuposto distinto: considera que a mudança é uma característica dos partidos, os quais raramente permanecem os mesmos entre uma eleição e outra. Por conseguinte, ela pondera ser um equívoco supor que apenas novos partidos apresentam "novidade" e que a continuidade ou a maturidade de uma legenda implica imobilismo, pois "um partido pode mudar de várias maneiras e em graus variados, tornando-se mais ou menos novo" (LITTON, 2015, p. 2).

Face a este entendimento, os propósitos da autora são: (1) abrir mão da dicotomia antigos e novos partidos; (2) capturar a fluidez da mudança partidária entre os ciclos eleitorais. Mais do que um ponto a alcançar, o primeiro é o pressuposto que serve de base para o segundo, o qual se realiza por meio da construção de um índice 
capaz de integrar os diferentes modos como mudam os partidos ou como se expressa o continuum da "novidade partidária", o que até então vinha sendo apresentado de forma fragmentária ou parcial. Por esta expressão, Litton (2015, p. 3) entende a "qualidade não cumulativa que reflete o grau de mudança de um partido em termos de afiliação estrutural e de seus atributos de marca em um ciclo eleitoral".

O índice de "novidade partidária", portanto, integra duas dimensões das mudanças dos partidos: os atributos de marca e a afiliação estrutural. A autora o organiza como um gráfico de dispersão, no qual a localização de cada partido corresponde à combinação dessas duas dimensões de análise, o que permite identificá-los no continuum.

Em cada dimensão, ela parte da ausência de mudança para sucessivos graus de novidade, os quais são organizados conforme a redução do potencial grau de reconhecimento do partido pelos eleitores. Ou seja, mais novidades partidárias correspondem a menos condição de ele ser identificado pelo público com o que era antes.

Em termos de atributos de marca, a alteração se refere a nome, liderança e programa ou a combinação entre eles. $\mathrm{O}$ ordenamento tem os seguintes estágios de mudança: (1) ausência; (2) programa; (3) líder ${ }^{25}$; (4) programa e líder; (5) nome ${ }^{26}$; (6) nome e programa; (7) nome e líder; (8) nome, líder e programa.

Em termos estruturais ou organizacionais, a medição inclui: (1) sem alteração; (2) abandonou a lista eleitoral pela qual concorreu ${ }^{27}$; (3) juntou-se a outra lista ${ }^{28}$; (4) expandiu-se por fusão ou recebeu a adesão de elites vindas de outros partidos; (5) sofreu cisão ou

25 A autora o descreve como uma pessoa, aquela identificada e reconhecida como a "principal" do partido em razão da exposição à mídia, ainda que outras exerçam a função de presidente ou de porta-voz. Portanto, pretende se referir à "liderança efetiva" e que não necessariamente está vinculada a posições formais de liderança (LITTON, 2015, p. 4).

26 Considerado como a denominação oficial e/ou aquela que adota em seu manifesto ou site, assim como a sigla que utiliza (LITTON, 2015, p. 4).

27 Na eleição anterior, o partido participou de uma coligação e, nesta, passou a concorrer com lista própria e autônoma (LITTON, 2015, p. 4).

28 É o inverso da anterior: o partido passou a compor uma coligação, quando no pleito anterior concorreu com lista própria e autônoma (LITTON, 2015, p. 4). 
deserção de elite; (6) surgiu novo partido da fusão de partidos anteriormente existentes; (7) surgiu novo partido da divisão de um previamente existente; (8) surgiu novo partido da dissolução de um anteriormente existente ${ }^{29}$; (9) surgiu do zero.

De um lado, ao considerar o grau de novidade, este modelo é tributário da ideia de Sikk (2005), segundo a qual apenas os partidos genuinamente novos são novos e todos os demais, em alguma medida, dão prosseguimento a partidos já existentes, o que reforça a continuidade mais do que a ruptura. Aliás, os critérios sugeridos pela definição de Sikk (2005, p. 399) também são aplicados por Litton (2015): nome, liderança e estrutura, tendo acrescentado mais um, programa.

De outro, o modelo desenvolve critérios formais de medição da novidade, com a intenção de objetivar parâmetros de distinção e/ ou de classificação que muitos dos autores vistos anteriormente haviam relacionado de modo quase intuitivo.

A proposta de Litton (2015) parece por em xeque toda a literatura sobre novos partidos, na medida em que considera a "novidade" como peculiaridade que todas as legendas podem apresentar. Consequentemente, o modo como a categoria tem sido concebida - e foi apresentada até aqui - se mostraria equivocado. Não haveria novo partido, mas sim aquele com maior ou menor grau de novidade.

Contudo, ao se observar o modo como ela operacionaliza este pressuposto epistemológico, verifica-se que não cumpriu o propósito que lhe serve de base, o de dispensar a dicotomia antigos e novos partidos. De fato, o que ela faz é remodelar a noção de novo partido, caso contrário o modelo padece de contradições em sua construção lógica. Litton (2015) considera equivocado o conceito de novo partido porque, ao se centrar na "novidade", suscita a ideia de que apenas eles possuem tal característica, o que anula ou

29 A extinção pode ser legalmente oficializada ou ocorrer apenas de fato, mas Litton (2015, p. 5) alerta que "um dos desafios de codificar partidos nesta categoria inclui o fato de que existe uma linha muito fina entre grupos de partidos que permanecem intactos com novos nomes, líderes e programas e grupos de partidos que emergem da dissolução com mudanças de liderança". 
minimiza o reconhecimento das possibilidades de mudanças que os partidos já estabelecidos apresentam. Isto não significa dizer que a autora negue a existência de novos partidos, mas sim que os rejeita como detentores do monopólio da novidade. Se não fosse assim, não teria sentido que, em termos de estrutura de organização, ela tenha afirmado a existência de quatro categorias de novos partidos (fusão, cisão, dissolução e do zero).

Se a interpretação que está sendo feita da proposta for procedente, este aspecto contamina o segundo objetivo. $\mathrm{O}$ modelo sugerido para capturar a fluidez da mudança partidária entre os ciclos eleitorais apresenta algumas fragilidades que serão comentadas a seguir.

A primeira é que há a intenção de criar um índice capaz de medir o grau de novidade concebido como um continuum. Para tal, ele é formado por duas dimensões organizadas de modo ordinal. $\mathrm{O}$ problema é que apenas uma delas é construída efetivamente como ordinal, a outra foi apresentada sob esta forma, mas não o é.

Os atributos de marca utilizados (nome, programa e liderança) abarcam características compartilhadas por todos os partidos e o modo como elas estão dispostas compõe diferentes categorias que os distinguem entre si, em uma classificação ordinal e discreta. A afiliação institucional não, são variáveis nominais que abarcam um atributo obrigatoriamente não compartilhado pelos partidos, pois cada corresponde a uma categoria diferente, necessariamente excludente em relação às demais. Logo, se um partido é novo oriundo de cisão, ele obrigatoriamente não o é decorrente de fusão e tampouco pode ser já existente etc.

A segunda fragilidade é que, como os eixos $\mathrm{x}$ e $\mathrm{y}$ do gráfico correspondem a atributos diferentes, o continuum não é tão contínuo assim, padecendo de ampla dose de determinação prévia. Isto porque cada modalidade de afiliação institucional já traz em si um certo (mas inicialmente desconhecido) potencial de "novidade", razão pela qual a própria distinção ocorre. Mas os atributos de marca, por serem características compartilhadas por todos os partidos, expressam a gradação da distinção. Em outras palavras: a inserção de um partido em determinada categoria de afiliação 
institucional exige aplicar um critério de classificação não explicitado, enquanto o mesmo procedimento em termos de atributo de marca explicita o critério utilizado.

Consequentemente, o enquadramento em cada categoria de afiliação institucional traz em si uma determinação prévia ou ampla expectativa vinculada ao grau de renovação nos atributos de marca. É o que se verifica, por exemplo, no modo como a autora operacionaliza a categoria "novo surgido de fusão":

se dois partidos de qualquer tamanho juntaram seus esforços para criar um novo partido. Uma nova entidade política envolveria a criação de uma nova liderança, regras de associação e aparato organizacional. A reciclagem de nomes, líderes e programas antigos é teoricamente aceita, embora isso não seja comum neste grupo (LITTON, 2015, p. 4).

Desse modo, ao ser aplicado ${ }^{30}$, o modelo encontrou alto grau de redundância ou de expectativas confirmadas, seja porque elas compõem o modo como a categoria é construída, seja porque determinadas combinações são logicamente inviáveis. Os novos partidos em termos organizacionais (categorias 6 a 9) jamais registraram casos em quatro atributos de marca: ausência de alterações (categoria 1); mudança apenas de programa (categoria 2); de líder e de programa (categoria 4); de nome e de programa (categoria 6). Alguns poucos tiveram mudança apenas de liderança (categoria 3); de nome (categoria 5); de nome e de liderança (categoria 7), mas a maioria apresentou o grau máximo de alteração, ou seja, de nome, de programa e de liderança (categoria 8). Já os partidos que haviam disputado a eleição anterior do ponto de vista organizacional (categorias 1 a 5) figuram em todas as categorias possíveis de mudança de atributos de marca, embora em quantidades variáveis.

A terceira fragilidade dá sequência às anteriores, assim como recupera o não cumprimento do pressuposto analítico do modelo.

30 Foram analisados partidos que concorreram ao parlamento europeu entre 1989 e 2009, em um total de quatro comparações e 333 partidos observados pertencentes a 25 países. 
Já foi indicado que, embora negue na teoria, a autora trabalha com a noção de novos partidos na prática, tanto que há quatro categorias de organização institucional que incluem tal denominação (números 6 a 9).

Os desdobramentos da noção de Hug (2001) podem ser resgatados novamente para balizar a distinção na qual a autora se baseia: os novos não existiam como tal no ciclo eleitoral anterior e os antigos, sim. O que Litton (2015) não faz, como já foi destacado repetidas vezes, é associar apenas os primeiros à novidade, pois ela se dispõe a verificar o grau de novidade que cada um apresenta. Porém, cabe perguntar: a partir de qual parâmetro alguns partidos podem ser considerados novos e distintos dos demais (os antigos), se a novidade é um continuum e se se verifica por um compósito de dois critérios? Na mesma linha: se o partido pode mudar de nome, de programa e de liderança, como é possível identificar que ele não disputou a eleição anterior (e é novo) e não se trata de um antigo partido "renovado"?

Pelo que se interpreta, esta classificação só pode ser feita ao relacionar a condição institucional aos atributos de marca. Logo, a determinação do partido como novo (em qualquer das modalidades), para não ser prévia e artificialmente estabelecida, tem de ser construída em relação ao critério de marca (nome, programa e liderança) - de modo semelhante ao que formula Sikk (2005) e ao que indicam diversos outros autores, ainda que sem sistematizarem os critérios que aplicaram.

Entretanto, no modelo de Litton (2015), um partido já é previamente considerado novo e, em sendo, apresenta $\mathrm{x}$, y ou $\mathrm{z}$ graus de novidade em termos de atributos de marca. Volta-se ao ponto de partida: mas por que ele é novo? Essencialmente, porque foi assim definido pelo pesquisador?

Este problema se manifesta nos casos de cisão e de fusão, as categorias gêmeas, aquelas em que há partidos que se formam por esta razão, sendo novos, bem como antigos que sofrem esse processo e que continuam sendo identificados como tal. Na aplicação do modelo aos casos analisados, a autora encontra novos e antigos 
partidos que passaram/surgiram por cisão ou por fusão e que apresentam o mesmo grau de novidade em termos de atributos de marca. Em síntese: no que tange a esses atributos de marca compartilhados, o que os distingue e os posiciona em determinado ponto do gráfico (e do continuum) é o fato de terem sido considerados novos ou antigos em termos de afiliação institucional. Novamente: por que nesses casos um é novo e o outro não, como e por que eles foram classificados diferentemente? Há um hiato, uma carência e os critérios não são especificados.

Pode-se ir mais longe: o patamar máximo no eixo estrutura de afiliação é compreendido pelo partido "surgido do zero". Nenhum critério é apresentado para indicar quais elementos permitem configurar uma legenda como tal, ela simplesmente é assim classificada pela pesquisadora. A não ser que este enquadramento seja o resultado do cruzamento com o mais avançado estágio de novidades nos atributos de marca, qual seja: ter concomitantemente um novo líder, um novo nome e um novo programa.

Concebido desse modo, o partido surgido do zero - que nada mais é do que o tipo genuinamente novo, de formação natural ou de nascimento, aquele considerado por todos os autores como inequivocadamente novo - torna-se tautológico: não há como ele ser "surgido do zero" sem estar, automaticamente, no ponto mais alto das novidades em termos de atributos de marca. Aliás, é o que se observa na aplicação dos critérios aos casos analisados no artigo (LITTON, 2015, p. 9).

Por tudo o que foi afirmado acima, considera-se que a proposta não cumpre o objetivo de construir um continuum capaz de abarcar os diferentes graus de novidade que os partidos podem apresentar. Na prática, a autora constrói dois continua, os quais são apresentados no mesmo gráfico.

No primeiro figuram os partidos antigos em termos de afiliação institucionais, os quais se distinguem entre si pelo grau de novidade que apresentam nos atributos de marca, além do modo como estão subdivididos no que tange à estrutura institucional. Na representação gráfica efetivada por Litton (2015, p. 9) eles estão sempre 
posicionados nos quadrantes inferiores. No segundo continuum estão, também em termos de afiliação institucional, os novos partidos. Eles se distinguem entre si pelo grau de novidade que apresentam nos atributos de marca, assim como se subdividem no que se refere à estrutura institucional. E, obrigatoriamente, sempre ocupam os quadrantes superiores do gráfico.

Dessa maneira, como estão obrigatoriamente sempre separados, o modelo é ineficaz para distinguir conceitualmente partidos novos e antigos - talvez por isto, a autora proponha romper com esta ideia, embora, na prática, não o faça. Ele também é ineficaz para fornecer elementos objetivos capazes de operacionalizar a distinção entre eles, que se sustenta implicitamente, apesar de se propor a tal por meio do indicador "grau de novidade". Esta é uma dificuldade que acompanha a literatura que trata do tema, na qual apreciações e critérios subjetivos movem as decisões, sem que um consenso tenha sido estabelecido.

Contudo, a proposta de Litton (2015) é valiosa para sistematizar a distinção do grau de novidade em termos de atributos de marca que cada tipo de partido (novo ou antigo) apresenta, o que, de fato, tem sido esquecido, menosprezado pela literatura ou não tem sido operacionalizado de modo eficiente. Embora o objetivo apresentado não tenha sido este, considera-se que o ponto positivo do modelo é estar aberto à possibilidade de que antigos partidos sofram alguma modificação, dispor-se a dimensioná-la, mas, ainda assim, continuar a considerá-los antigos; e, da mesma forma, que os novos possam ser distinguidos entre si no que tange ao grau de novidade que ostentam.

Sob perspectiva diferente da aqui apresentada, a própria autora destaca este mérito, quando explicita que a "novidade partidária" deve ser vista como um todo e que, consequentemente, nenhum dos dois critérios pode ser considerado separadamente. E exemplifica: não se pode pressupor que partidos que sofreram cisão tenham mais novidade do que aqueles que se expandiram por fusão, sem saber se esses partidos mudaram alguns de seus atributos de marca no processo. Ou seja, não é porque a cisão implica 
grau mais elevado de novidade do que a fusão que se pode supor, automaticamente, que uma legenda que passar por esta mudança organizacional apresentará índice final de novidade mais intenso do quw outra fusionada. É preciso considerar, ainda, as implicações em termos de atributos de marca que acompanham (ou não) esta mudança estrutural (LITTON, 2015, p. 3).

No que tange aos novos partidos, aliás, Litton (2015) segue a trilha proposta por Krouwel e Lucardie (2008), que distinguiram os novos partidos pelo grau de novidade. Mas, ela vai além, pois operacionaliza os critérios e amplia o olhar para abarcar os partidos já estabelecidos, os quais, na perspectiva da autora, também mudam.

A intenção é a de organizar um continuum do grau de novidade, ao integrar dois critérios. Porém, não é exatamente este o resultado alcançado, pois o modo como as categorias de afiliação institucional estão formuladas já trazem em si significativa distinção no grau de novidade. A divisão dessas categorias implica diferenças entre os partidos que provavelmente vão se manifestar em atributos de marca, o que faz com que o modelo seja bastante pré-determinado e o enfraquece no cumprimento da intenção distintiva que o move.

Não é por acaso que o exemplo citado pela autora envolva duas modalidades de "novos partidos". De fato, o grau de novidade acumulado entre um partido de cisão e outro de fusão, quando são incorporados atributos de marca, pode ser maior que aquele esperando, quando é analisado apenas o critério afiliação institucional. Independentemente disso, eles não deixam de ser "novos" e não se confundem com os "antigos".

Em outras palavras: é muito provável que os antigos partidos, exatamente por serem considerados antigos, tenham menor grau de novidade do que os novos. Se a constatação negar esta expectativa, talvez o enquadramento em determinada categoria de afiliação institucional esteja equivocado. A dificuldade é, portanto, circular: se independe dos atributos de marca, pois categorias de afiliação institucional podem ter mais ou menos novidade em termos desses atributos, qual o critério para incluir um partido em cada categoria e qual o ponto de corte entre um partido novo e antigo? 
Nesse sentido, Litton (2015) não oferece solução ao principal desafio dessa literatura, que é desenvolver critérios mais objetivos e menos intutivos ou idiossincráticos para classificar (ou não) um partido oriundo de transformação, cisão ou fusão como novo considerando existir um consenso em torno do enquadramento do "genuinamente novo" -, apesar fornecer e organizar parâmetros em termos de atributos de marca que, justapostos, podem auxiliar nesta tarefa.

\section{Considerações finais}

$\mathrm{O}$ artigo procurou discutir as diferentes concepções desenvolvidas pela Ciência Política em torno da categoria novos partidos, tendo sido promovido por meio de revisão da literatura contemporânea sobre o tema. A intenção foi fornecer elementos que a tornassem teoricamente orientada e metodologicamente operacional para o desenvolvimento de estudos empíricos rigorosos sobre as diferentes formações institucionais que esses partidos desenvolvem.

A primeira distinção gira em torno de considerar tão somente os partidos eleitorais ou incluir aqueles que não ainda participaram desses eventos. Prepondera o vínculo com o pleito, como se verificou na maioria dos autores, em especial na definição de Hug (2000, 2001). Contudo, desvincular a categoria deste evento pode ser mais adequado para abarcar os casos verificáveis em democracias não-estáveis ou processos de redemocratização, nos quais os partidos que já existem oficialmente como tal - alguns inclusive atuam no parlamento -, mas não enfrentaram as urnas, seja porque as eleições ainda não aconteceram, seja porque, tendo elas ocorrido, circunstancialmente decidiram não concorrer, como sugere Aït-Aoudia (2016).

A segunda divisão envolve o significado do termo novo. Um de seus ramos o discute no sentido cronológico. Aqueles que o vinculam à eleição não estabelecem a exigência de o partido ser recém-criado, pois é requisitado tão somente que estreie em disputas nacionais. A visão que os desvincula do processo eleitoral considera necessário 
que sejam de criação/oficialização recente em termos temporais. $\mathrm{O}$ outro ramo interpreta novo em termos de diferença de conteúdo em relação aos já existentes, como o fazem Barnea e Rahat (2010), o que pode ser atestado por meio de um novo nome e de novos candidatos preferenciais, mas traz como horizonte a expectativa de apresentar uma proposta programática inovadora. No entanto, a preferência dos pesquisadores recai em não incluir tal exigência, pois o novo partido deve ser considerado distinto simplesmente por implicar uma nova oferta e um novo competidor no mercado partidário.

A terceiro celeuma abarca a origem ou o status institucional daqueles que devem ser considerados novos partidos. Há o consenso em torno dos chamados genuinamente novos, formados por indivíduos e/ou organizações sem vínculo com o sistema partidário. Todas as demais modalidades implicam algum grau de divergência entre os pesquisadores, a partir da qual há a exclusão de algumas situações.

A maioria dos autores reconhece mais novidade na cisão, propondo como critério de decisão que o novo partido deve competir com a legenda da qual se separou. Mas eles se dividem nos casos de fusão. Alguns a repudiam simplesmente. E, dentre aqueles que a incluem, surgem diferentes parâmetros a serem seguidos, dentre os quais se destaca o sugerido por Bolleyer (2013): o partido oriundo da fusão deve implicar a extinção dos formadores, com vistas a distinguir dos casos em que um partido absorve outros e, embora eventualmente mude de nome e inclua novas lideranças como parte desse processo, continua a ser reconhecido como aquele que incorporou parceiros menores.

A modalidade menos consensual é o chamado partido por transformação, proposto por Krouwel e Lucardie (2010), correspondente a um partido estabelecido que, sem passar por fusão, revisa seu programa, busca novos grupos de eleitores e/ou altera seu nome. A tendência dos pesquisadores é não o considerar como novo ou tratá-lo como um caso limite, a ser apreciado caso a caso. Arter (2012) sugere uma especificação, que é o partido sucessor. Este, 
assim como os oriundos de fusão, é novo porque se registra como uma nova entidade, mas possui os mesmos líderes e, eventualmente, o mesmo programa de uma legenda que se extinguiu.

Por fim, há as contribuições de Barnea e Rahat (2010) e de Litton (2015), as quais, a partir de propósitos diferentes, apresentam critérios a serem seguidos para classificar a novidade dos partidos e, assim, poder considerá-los novos - como buscam os primeiros - ou identificar o grau de inovação que apresentam - como sugere a segunda.

Litton (2015), em particular, considera que todos os partidos podem apresentar novidade e, portanto, não é a presença dela que identifica um novo partido. O resultado a que ela chega não produz o pretendido continuum do grau de novidade capaz de integrar antigos e novos partidos, e sim fornece parâmetros em termo de atributos de marca (nome, programa e liderança) capazes de distinguir o grau de novidade que as legendas apresentam, considerando separadamente as novas e as antigas, assim como a respectiva afiliação institucional de cada subtipo.

\section{Referências}

AÏT-AOUDIA, Myriam (2016). “Conditions for new parties' participation in a founding election in a democratic transition: the Algerian case". Party Politics, p. 1-10. Disponível em: $<$ https://doi.org/10.1177/1354068816667387>.

ARTER, David (2012). "Analysing 'successor parties': the case of the True Finns”. West European Politics, v. 35, n. 4, p. 803-825.

BARNEA, Shlomit; RAHAT, Gideon (2010). "Out with the old, in with the 'new': what constitutes a new party?" Party Politics, v. 17, n. 3, p. 303-320.

BOLIN, Niklas (2014). "New party parliamentary entry in Western Europe, 1960-2010". European Journal of Government and Economics, v. 3, n. 1, p. 5-23.

BOLLEYER, Nicole (2013). New parties in old party systems: persistence and decline in seventeen democracies. New York: Oxford University Press. 
BOLLEYER, Nicole; BYTZEK, Evelyn (2016). "New party performance after breakthrough: party origin, building and leadership". Party Politics, v. 23, n. 6, p. 772-782.

BOLLEYER, Nicole; BYTZEK, Evelyn (2013). "Origins of party formation and new party sucess in advanced democracies". European Journal of Political Research, n. 52, p. 773-796.

COX, Gary W. Make votes count: strategic coordination in the world's electoral systems. Cambridge: Cambrigde Oxford Press, 1997.

DUVERGER, Maurice (1987). Os partidos políticos. 3ed. Rio de Janeiro: Guanabara.

HARMEL, Robert (1985). “On the study of new parties". International Political Science Review, v. 6, n. 4, p. 403-418.

HARMEL, Robert; ROBERTSON, John D. (1985). "Formation and success of new parties: a cross-national analysis". International Political Science Review, v. 6, n. 4, p. 501-523.

HUG, Simon (2001). Altering party systems: strategic behavior and the emergence of new political parties in western democracies. Ann Arbor: University of Michigan Press.

HUG, Simon (2000). "Studying the success of new political parties". Party Politics, v. 6, n. 2, p. 187-197.

KROUWEL, André; LUCARDIE, Paul (2008). "Waiting in the wings: new parties in the Netherlands". Acta Politica, v. 43, n. 2-3, p. 278-307.

LIPSET, Seymor; ROKKAN, Stein (1967). Party system and voter alignements: cross national perspectives. New York: Free Press.

LITTON, Krystyna (2015). "Party novelty: conceptualization and measurement of party change". Party Politics, v. 21, n. 5, p. 1-14.

KITSCHELT, Herbert. The logics of party formation: ecological politics in Belgium and West Germany. Ithaca: Cornell University Press, 1989.

MAIR, Peter (1999). "New political parties in long-established party systems: how successful are they?" In BEUKEL, E. K.; KLAUSEN, K. K.; MOURITZEN, P. E. (Eds). Elites, parties and democracy: festschrift for Professor Mogens N. Pedersen. Odense: Odense University Press, p. 207-224. 
MAIR, Peter (1990). "The electoral payoffs of fission and fusion". British Journal of Political Science, v. 20, n. 1, p. 131-142.

MARINOVA, Dani (2015). "A new approach to estimating electoral instability in parties". Political Science Research and Methods, v. 3, n. 2, p. 1-16.

MUSTILLO, Thomas J. (2009). "Modeling new party performance: a conceptual and methodological approach for volatile party systems". Political Analysis, n.17, p. 311-332.

PEDERSEN, Mogens N. (1982). "Towards a new typology of party lifespans and minor parties”. Scandinavian Political Studies, v. 5, n. 1, p. 1-16.

POWELL, Eleanor Neff; TUCKER, Joshua A. (2014). "Revisiting electoral volatility in post-communist countries: new data, new results and new approaches". British Journal of Political Science, v. 44, n. 1, p. 123-147.

SIKK, Allan (2005). "How unstable? Volatility and the genuinely new parties in Eastern Europe". European Journal of Political Research, v. 44, p. 391-412.

TAVITS, Margit (2008). "Party systems in the making: the emergence and success of new parties in new democracies". Britsh Journal of Political Science, v. 38, n. 1, p. 113-133.

TAVITS, Margit (2006). "Party system change: testing a model of new party entry". Party Politics, v. 12, n. 1, p. 99-119.

VAN BIEZEN, Ingrid; RASHKOVA, Ekaterina (2014). "Deterring new party entry? The impact of state regulation on the permeability of party systems". Party Politcs, v. 20, n. 6, p. 890-903.

\section{Resumo}

O artigo discute o modo como a Ciência Política tem definido os novos partidos, com o objetivo aprimorar a construção desta categoria, de forma a torná-la metodologicamente apta a classificar as diferentes conformações institucionais que os partidos apresentam e, consequentemente, poder dimensionar os resultados que produzem nos sistemas partidários nacionais. Aborda especificamente o modo como devem ser considerados os partidos oriundos de transformação e/ou de 
sucessão de um já existente, aqueles surgidos em razão de cisão sofrida por legenda estabelecida ou de fusão entre partidos, assim como aqueles sem vínculos com qualquer partido vigente. A investigação se baseia na contribuição de diferentes analistas internacionais que se debruçam sobre a questão desde o final dos anos 1970, quando o fenômeno se tornou recorrente.

Palavras-chave: novos partidos; fusão; cisão; transformação; sucessor

\section{Abstract}

The article discusses the way how Political Science literature has been defining the new parties. Through this debate, it aims to improve the construction of this category, in order to make it methodologically apt to classify the different institutional conformations that the parties present and, consequently, to be able to size the results that it produces in the national party systems. It approaches specifically with the way in which they should be considered: parties arising from transformation and / or succession from an already existing party, those arising from a split by established legend or a merger between parties, as well as those with no ties with any current party. The investigation is based on the contribution of different international analysts who look at the issue since the late 1970s, when the phenomenon became recurrent.

Keywords: new parties; merger; split; transformation; successor

Recebido em: 25 de outubro de 2018

Aprovado em: 21 de dezembro de 2018 